\title{
Inflammatory Myofibroblastic Tumor in the Bladder: A Case Report
}

\author{
Takuya Kondo $^{a}$ Takashi Kawahara $^{\mathrm{a}, \mathrm{b}}$ Sawako Chiba ${ }^{\mathrm{c}}$ Mari Ohtaka $^{\mathrm{a}}$ \\ Yohei Kumano $^{\text {a }}$ Yoko Saitoh $^{\mathrm{a}}$ Taku Mochizuki $^{\mathrm{a}}$ Yusuke Hattori $^{\mathrm{a}}$ \\ Jun-ichi Teranishi $^{\mathrm{a}}$ Yasuhide Miyoshi $^{\mathrm{a}}$ Yasushi Yumura $^{\mathrm{a}}$ \\ Masahiro Yao $^{b}$ Yoshiaki Inayama $^{c}$ Hiroji Uemura $^{a}$ \\ ${ }^{a}$ Departments of Urology and Renal Transplantation, Yokohama City University Medical \\ Center, Yokohama, Japan; ${ }^{b}$ Department of Urology, Yokohama City University Graduate \\ School of Medicine, Yokohama, Japan; 'Department of Diagnostic Pathology, Yokohama \\ City University Medical Center, Yokohama, Japan
}

\section{Keywords}

Inflammatory pseudotumor $\cdot$ Inflammatory myofibroblastic tumor $\cdot$ Bladder tumor

\begin{abstract}
A 36-year-old male was referred to our department for further examination of asymptomatic gross hematuria emanating from a bladder tumor. Cystoscopy revealed a broad-based tumor $40 \mathrm{~mm}$ in diameter. Urinary cytology was negative. Preoperative magnetic resonance imaging suggested a muscle invasive tumor. Transurethral resection was performed, and the pathological findings revealed an inflammatory myofibroblastic tumor. We herein report a rare case of bladder inflammatory myofibroblastic tumor.

(C) 2016 The Author(s) Published by S. Karger AG, Basel
\end{abstract}

\section{Introduction}

Inflammatory myofibroblastic tumor (IMT) is rare and characterized by spindle cell proliferation with inflammatory cell infiltration. The majority of patients have an indolent clinical course. Because of its cytological features and infiltrative nature, it may be difficult to 
distinguish histologically from malignant sarcomatous lesions [1]. This tumor can occur in any organ. The incidence of IMT is reported to be 6 out of 2,050 bladder tumors [2].

\section{Case Presentation}

A 36-year-old male was referred to our hospital for further examination of a bladder tumor. Cystoscopy revealed a broad-based tumor $40 \mathrm{~mm}$ in diameter (fig. 1). He had a medical history of hyperlipidemia, diabetes mellitus, asthma, and bipolar disorder.

\section{Laboratory Data and Imaging Findings at the Time of Admission}

The hematological and biochemical data showed no abnormal findings without elevation of HbA1c of 8.4\%. The tumor markers were also within normal limits (CEA $1.4 \mathrm{ng} / \mathrm{ml}$, CA125 $12 \mathrm{U} / \mathrm{ml}$, CA19-9 $7 \mathrm{U} / \mathrm{ml}$ ). Magnetic resonance imaging (MRI) showed a $40 \times 25-\mathrm{mm}$ mosaic bladder mass of high intensity on diffusion images; the tumor was suspected to have invaded the muscle (fig. 2), but computed tomography revealed no distant metastasis.

\section{Operative Procedure and Pathological Findings}

The patient underwent transurethral resection of his bladder tumor. Histologically, the urothelium showed no atypia. In the submucosa, spindle cells proliferated in interlacing fascicles or storiform arrays with inflammatory cell infiltration. The spindle tumor cells had no obvious pleomorphism and mitoses (fig. 3). Immunohistochemically, the spindle tumor cells were strongly positive for anaplastic lymphoma kinase (ALK) and smooth-muscle actin, weakly positive for cytokeratin AE1/AE3 and p53 but negative for desmin. Based on these findings, the tumor was diagnosed as IMT.

\section{Postoperative Course}

No adverse perioperative events were observed. The patient has not experienced recurrence in the 10 months since resection of the bladder tumor.

\section{Discussion}

IMT - also known as postoperative spindle cell nodule, pseudosarcomatous fibromyxomatous tumor, and reactive pseudosarcomatous response - involve only inflammatory cells. These tumors have been observed in any organ, including the lung, liver, and kidney. Roth et al. [3] reported the first case of IMT in the bladder.

The most frequently reported symptom is gross hematuria followed by urinary pain, dysuria, and increased urination frequency. The tumor has been observed in a wide range of ages, from around 30 to 50 years, with an equal balance of genders. Although the causes of this tumor have long been believed to be urinary tract infection, surgical invasion, diabetes mellitus, and immune disorders, a number of idiopathic cases have also been reported $[4,5]$. In our case, the patient had diabetes mellitus. In this case, the tumor size was around $4 \mathrm{~cm}$ in diameter. Reported IMTs were around 2-5 cm in most cases, but 1 case showed $37.5 \mathrm{~cm}$ [1, 4]. Due to the risk of local recurrence, complete resection is recommended [6]. On the other hand, some tumors were treated by steroids or anti-inflammatory drugs without radical treatment [7]. 
Grossly, IMT shows a variety of forms, but in most cases, the tumor adopts a nonpapillary form with a rounded surface. On MRI, the tumor typically shows low intensity on T1weighted imaging and high intensity at the surface with low intensity inside on T2-weighted imaging [8]. Our case showed almost the same findings.

Histologically, IMT is characterized by proliferation of myofibroblastic spindle cells and inflammatory cell infiltration. Recently, ALK protein expression in IMT has been reported. The most important entities in differential diagnosis are sarcomatoid urothelial carcinoma, leiomyosarcoma, and rhabdomyosarcoma because of the similarity of histological findings. Finding cytological atypia and atypical mitotic figures and immunostaining with ALK are useful to differentiate IMT from other malignant spindle cell tumors $[1,9]$.

All reported cases underwent transurethral resection of the bladder for a pathological examination. Although there have been no reports of distant metastasis, intravesicle recurrence was reported after transurethral resection [10]. Complete resection was subsequently needed. In cases with muscle invasion, partial bladder resection is required after transurethral resection. However, in cases of benign tumors, total cystectomy should not be performed due to the risk of misdiagnosing them as sarcomatoid carcinoma.

\section{Statement of Ethics}

The authors have no ethical conflicts to disclose.

\section{Disclosure Statement}

The authors declare that they have no competing interests.

\section{References}

1 Tsuzuki T, Magi-Galluzzi C, Epstein JI: ALK-1 expression in inflammatory myofibroblastic tumor of the urinary bladder. Am J Surg Pathol 2004;28:1609-1614.

-2 Elawdy MM, Harraz AM, Zahran MH, Abdelraheem, El-Baz M, El-Hefnawy AS: Inflammatory pseudotumor of the urinary bladder: a case series among more than 2,000 urinary bladder tumor cases. Urol Ann 2016;8:95-98.

3 Roth JA: Reactive pseudosarcomatous response in urinary bladder. Urology 1980;16:635-637.

-4 Jones EC, Clement PB, Young RH: Inflammatory pseudotumor of the urinary bladder. A clinicopathological, immunohistochemical, ultrastructural, and flow cytometric study of 13 cases. Am J Surg Pathol 1993;17:264-274.

-5 Gyftopoulos K, Serafetinidis E, Sambaziotis D, Archondakis A: Pseudomalignant spindle cell proliferation of the urinary bladder: an unusual cause of voiding symptoms in a young patient. Urology 2002;60:698.

6 Chan JK, Cheuk W, Shimizu M: Anaplastic lymphoma kinase expression in inflammatory pseudotumors. Am J Surg Pathol 2001;25:761-768.

-7 Berger A, Kim C, Hagstrom N, Ferrer F: Successful preoperative treatment of pediatric bladder inflammatory myofibroblastic tumor with anti-inflammatory therapy. Urology 2007;70:372 e313e375.

-8 Sugita R, Saito M, Miura M, Yuda F: Inflammatory pseudotumour of the bladder: CT and MRI findings. Br J Radiol 1999;72:809-811.

-9 Freeman A, Geddes N, Munson P, Joseph J, Ramani P, Sandison A, Fisher C, Parkinson MC: Anaplastic lymphoma kinase (ALK 1) staining and molecular analysis in inflammatory myofibroblastic tumours of the bladder: a preliminary clinicopathological study of nine cases and review of the literature. Mod Pathol 2004;17:765-771. 


\section{Case Reports in Oncology}

\begin{tabular}{l|l}
\hline Case Rep Oncol 2016;9:554-558 \\
\hline DOI: 10.1159/000449372 & $\begin{array}{l}\text { ○ 2016 The Author(s). Published by S. Karger AG, Basel } \\
\text { www.karger.com/cro }\end{array}$ \\
\hline
\end{tabular}

10 Iczkowski KA, Shanks JH, Gadaleanu V, Cheng L, Jones EC, Neumann R, Nascimento AG, Bostwick DG: Inflammatory pseudotumor and sarcoma of urinary bladder: differential diagnosis and outcome in thirty-eight spindle cell neoplasms. Mod Pathol 2001;14:1043-1051.

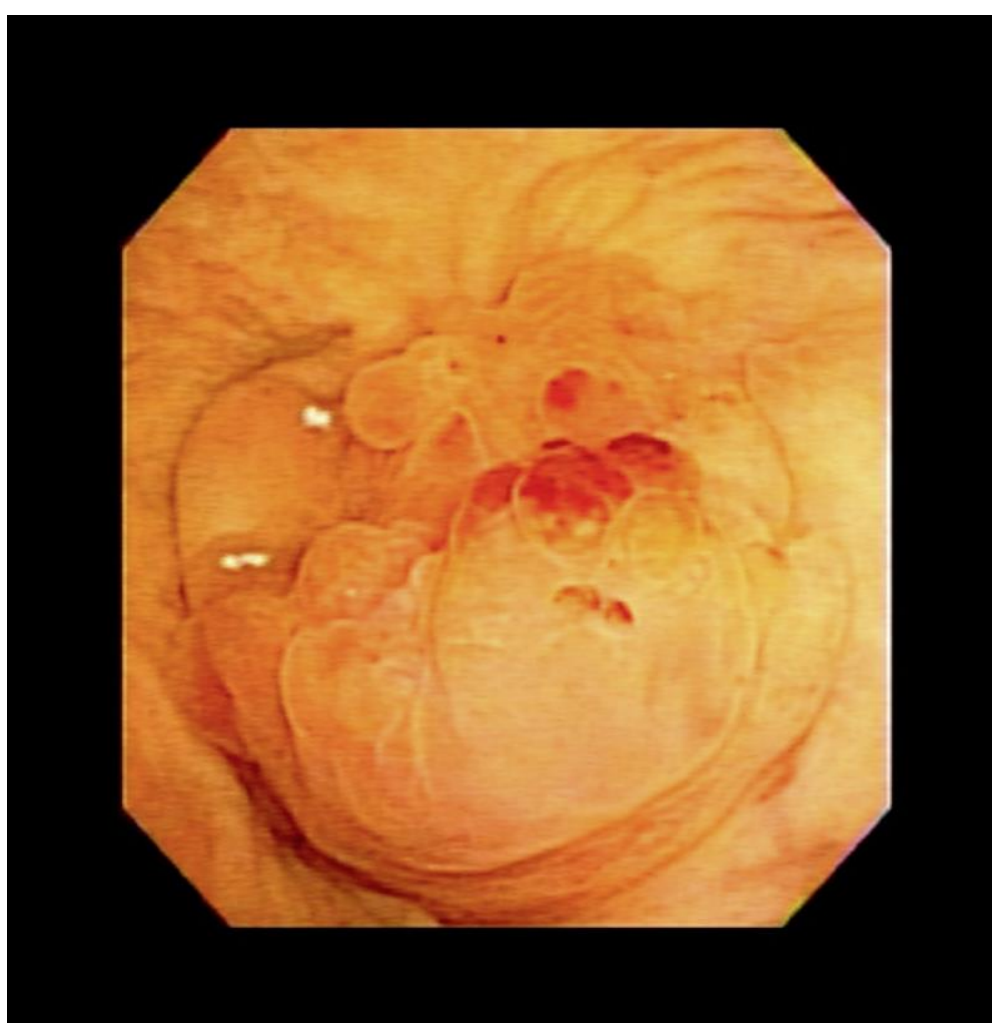

Fig. 1. Cystoscopic findings.
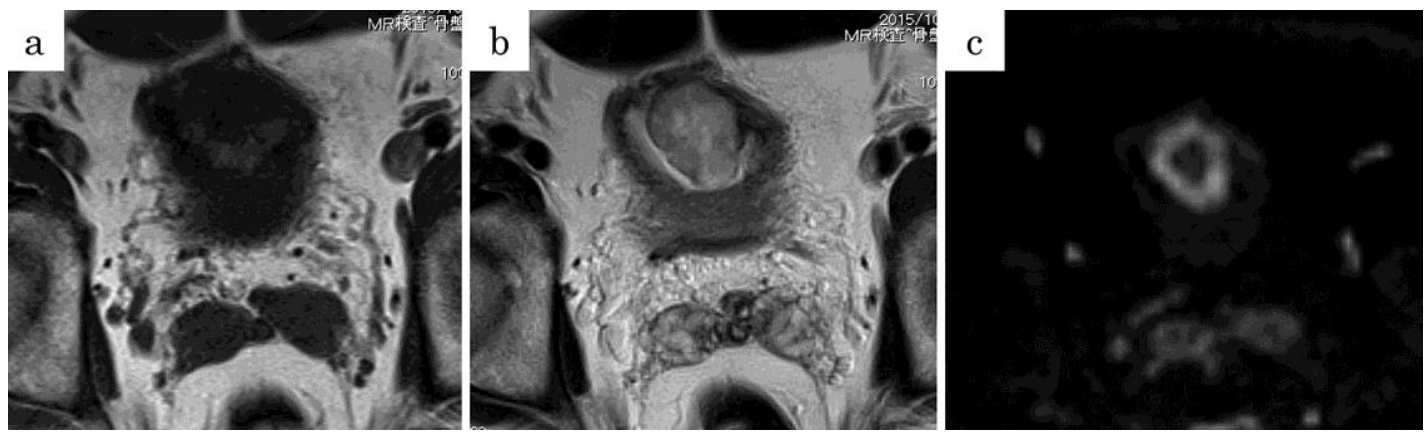

Fig. 2. MRI findings. a T1-weighted imaging. b T2-weighted imaging. c Diffusion. 


\section{Case Reports in Oncology

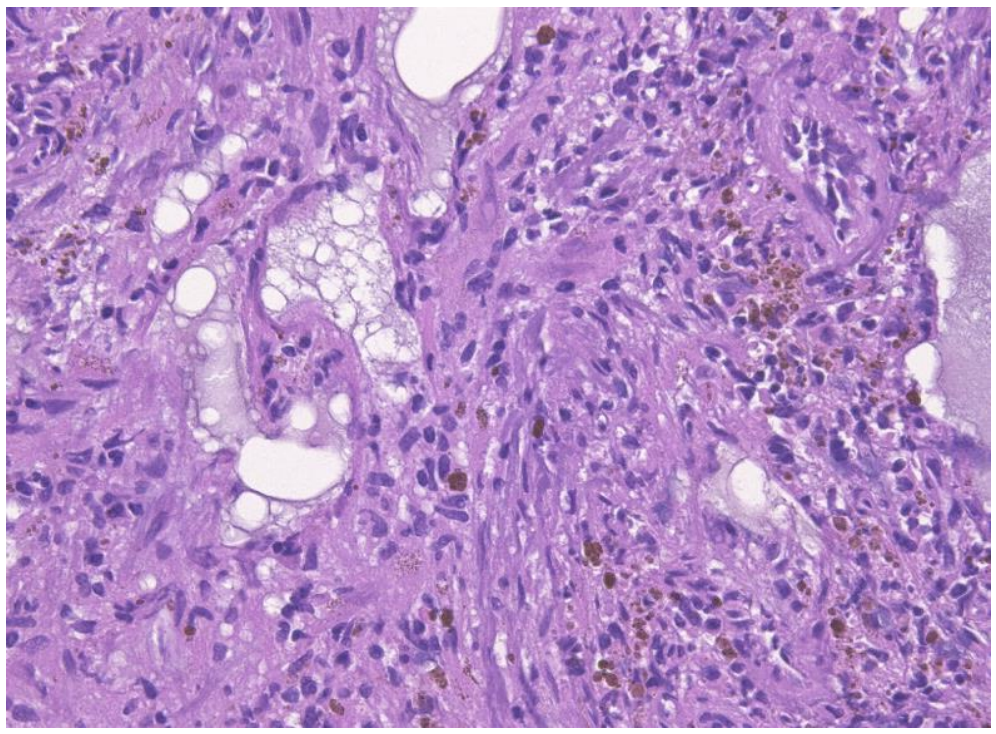

Fig. 3. HE staining. 